\title{
"SANEAMENTO" DA LITERATURA INFANTO-JUVENIL: O ESFORÇO DO CPOE E DA REVISTA DO ENSINO (RS)
}

\author{
A “CLEANUP" IN CHILDREN'S-JUVENILE LITERATURE: THE \\ EFFORT MADE BY THE CPOE AND THE TEACHING MAGAZINE \\ (RS)
}

DOI: http://dx.doi.org/10.15448/2178-3748.2015.2.19692

\author{
Eliane Teresinha Peres \\ Professora Doutora - PPGE/UFPEL \\ E-mail: eteperes@gmail.com
}

Mônica Maciel Vahl

Doutoranda em Educação - University of Canterbury

E-mail: monicamvahl@gmail.com

\begin{abstract}
RESUMO: Este artigo tem por objetivo discutir o esforço feito pela Comissão Especial de Estudo e Classificação de Publicações Periódicas do Centro de Pesquisas e Orientações Educacionais (CPOE) e pela Revista do Ensino de estabelecer um "saneamento" da literatura infantil e juvenil durante a década de 1950 no Estado do Rio Grande do Sul, Brasil. Os dados foram coletados a partir de documentos oficiais (Boletins, Decretos e Leis) e da imprensa pedagógica (exemplares da Revista do Ensino). A análise dessa experiência permitiu identificar formas de controle, disciplinamento e normatização da leitura e dos leitores em um período recente da História da Educação gaúcha. Além disso, os resultados apontam para o desenvolvimento de uma postura de vigilância em relação aos livros e as revistas que poderiam influenciar a 'formação moral' das gerações mais jovens. Inspiradas em um discurso que evocava como palavras-chave Escola, Família, Igreja e Estado foram adotadas estratégias de difusão de alguns impressos como as obras da Condessa de Ségur e estratégias de rejeição de outros como as revistas em quadrinhos "Tarzan" e "Capitão Marvel".

Palavras-chave: Literatura infanto-juvenil, Centro de Pesquisas e Orientações Educacionais, Revista do Ensino.
\end{abstract}

PALAVRAS CHAVE: Literatura infanto-juvenil, Centro de Pesquisas e Orientações Educacionais, Revista do Ensino

\begin{abstract}
This paper aims at discussing the effort made by the Special Committee on Study and Classification of Periodical Publications of the Center of Researches and Educational Orientation (CPOE) and by the Teaching Magazine to establish a "clean up" in children's-juvenile literature in the 1950's in Rio Grande do Sul state, Brazil. The data were collected in official documents (Bulletins, Decrees and Laws) and in the pedagogical media (Teaching Magazine). The analysis of this experience has enabled the identification of forms of control, acts of discipline and standardization of reading and readers in a recent period of the state Education History. In addition, the results indicate the development of a vigilance posture toward books and magazines that could influence the 'moral formation' of the younger generations. Inspired by a speech that evoked as keywords school, family, Church and State were adopted dissemination strategies of some printed matter as the work of Countess of Ségur and rejection strategies of others such as the comic books "Tarzan" and "Captain Marvel"..
\end{abstract}

KEYWORDS: Children's-juvenile literature, Center of Researches and Educational Orientation - CPOE/RS, Teaching Magazine.

\section{INTRODUÇÃO}


Este artigo aborda o esforço de estabelecer um "saneamento" da literatura infantil e juvenil identificadas nos trabalhos desenvolvidos pela Comissão Especial de Estudo e Classificação de Publicações Periódicas, do Centro de Pesquisas e Orientações Educacionais (CPOE) e pela Revista do Ensino no decorrer da década de 1950 no Rio Grande do Sul, Brasil. Os dados foram coletados através da análise de documentos oficiais (Boletins, Decretos e Leis) e dos exemplares da Revista do Ensino.

A Comissão Especial de Estudo e Classificação de Publicações Periódicas do CPOE foi nomeada em 1955 pelo então Secretário de Educação e Cultura, Liberato Salzano Vieira da Cunha e tinha como objetivo principal analisar e emitir pareceres sobre publicações infanto-juvenis, procurando promover "o saneamento moral das revistas, a fim de que possam circular livremente como meio de recreação sadia" (Rio Grande do Sul. Boletim do CPOE, 1958).

A Revista de Ensino, um periódico educacional apoiado em diversos momentos pela Secretaria de Educação e Cultura do Rio Grande do Sul, também procurou promover formas de controle no que se refere a literatura infantil e juvenil. Ao longo da década de 1950 foram publicados artigos que discutiam sobre a 'boa literatura' infanto-juvenil e divulgadas listas de livros recomendados seguidas de apreciações críticas nas seções Comentários Bibliográficos e Informações Bibliográficas.

Para uma melhor compreensão, este texto foi organizado em três partes. A primeira parte aborda aspectos gerais do contexto educacional gaúcho no início da segunda metade do século XX e discute a atuação da Comissão Especial de Estudo e Classificação de Publicações Periódicas do CPOE. A segunda parte trata das publicações da literatura infanto-juvenil na Revista do Ensino, em especial, da seção Comentários Bibliográficos. Por fim, a terceira parte apresenta algumas considerações sobre as tentativas de elaborar um saneamento da literatura infantil e juvenil no Rio Grande do Sul durante a década de 1950.

\section{A Comissão Especial de Estudo e Classificação de Publicações Periódicas do CPOE}

Em 1942 a Secretaria da Educação do Rio Grande do Sul passou por uma reorganização e foi denominada, então, de Secretaria da Educação e Cultura (SEC). Nessa reorganização foi criada, em substituição às antigas Inspetoria e Diretoria da Instrução Pública, o Departamento de Educação Primária e Normal. As funções desse Departamento eram, fundamentalmente, as de "exercitar, orientar e fiscalizar as atividades relativas à 
educação pré-primária, primária e normal, bem como o ensino supletivo" (Rio Grande do Sul. Decreto $n^{\circ} 578$, de 22/07/1942).

Um ano após essa reorganização, em 1943, foi aprovado o Regimento Interno do Departamento de Educação Primária e Normal e com ele instalado o Centro de Pesquisas e Orientação Educacionais (CPOE). A partir de então - e até os anos 70 - o CPOE desempenhou um papel fundamental no ensino primário do Rio Grande do Sul, tendo como função principal a "realização de estudos e investigações psicológicas, pedagógicas e sociais, destinados a manter em bases científicas o trabalho escolar" (Rio Grande do Sul. Decreto ${ }^{\circ}$ 794, de 17/06/1943).

Sobre o CPOE, Quadros e Stephanou afirmam que:

Sua ênfase em dotar a educação rio-grandense de bases científicas e experimentais, além da adoção do discurso da renovação educacional, permite afirmar que o CPOE/RS presidiu um processo de reforma educacional, que não se consubstanciou numa única lei ou decisão administrativa nomeada e datada como tal, mas um movimento de caráter reformador que promoveu a implementação de mudanças substantivas, podendo por isso fazer-se o uso da expressão reforma da educação (QUADROS; STEPHANOU, 2011, p. 98).

Eram competências do CPOE elaborar medidas para a organização das classes, a orientação educacional e o controle do rendimento escolar. Isso deveria se efetivar através de cursos e reuniões, de visitas às unidades escolares, de ensaios pedagógicos, de consultas de ordem técnica, da elaboração de programas, de planos, de comunicados, de circulares e de instruções, através da manutenção de uma Biblioteca Central de obras pedagógicas e escolares, da organização do conteúdo pedagógico do Boletim de Educação da SEC, da indicação de livros didáticos e de obras para as bibliotecas dos professores e dos alunos (Rio Grande do Sul. Decreto $n^{0}$ 794, de 17/06/1943).

O primeiro boletim do CPOE indicava, ainda, que suas atribuições estariam centradas na orientação técnico-pedagógica dos estabelecimentos de ensino e, para tanto, seriam realizados "estudos e investigações psicopedagógicas, destinadas a manter em bases científicas o trabalho escolar", e organizados "com fundamento nos estudos realizados, planos de trabalho, programas, comunicados, circulares e instruções”. Essas orientações por sua vez, iriam ser repassadas às escolas sob jurisdição da SEC (Rio Grande do Sul. Boletim do CPOE, 1947). 
O CPOE foi o responsável pela consolidação de um projeto político-pedagógico em que os saberes que se afirmavam como novos e científicos, proveram as bases para a centralização das atividades e para a constituição de diferentes formas de controle e vigilância (QUADROS, 2006). Entre as variadas facetas desse controle e vigilância, foi desenvolvida uma campanha de repressão contra as "publicações inadequadas à boa formação moral da infância e da juventude” (Rio Grande do Sul. Boletim do CPOE, 1952-1953).

No contexto pedagógico, político e religioso dos anos de 1950 no Rio Grande do Sul, os livros eram percebidos como elementos importantes na formação da infância e da juventude. Entretanto, a prática de leitura poderia ser perigosa, carecendo de ordenação, controle e regramento. As intervenções ocorriam no sentido de que as publicações consideradas 'sadias' circulassem com maior abrangência inculcando as condutas esperadas e que as 'más escolhas' fossem evitadas, sobretudo as revistas em quadrinhos (VENTORINI, 2009, 2010).

Havia uma preocupação com a influência que os livros e as revistas poderiam gerar na constituição do caráter e da consciência das crianças e dos adolescentes. Essa apreensão era fruto do entendimento que os educandos eram incapazes de "manter o poder da vontade em oposição a seus impulsos", sendo necessário um disciplinamento de suas vontades e a classificação desses materiais em 'boa' ou 'má' literatura (Rio Grande do Sul. Boletim do CPOE, 1952-1953)

Em 1955 foi instituída a Comissão Especial de Estudo e Classificação de Publicações Periódicas pela Portaria 3135 de 28/06/55. A Comissão era vinculada ao CPOE, e tinha como finalidade analisar e classificar as obras infanto-juvenis fazendo, assim, uma grande campanha em prol da boa literatura afim de reprimir a imprensa malsã e no sentido de que as Editoras pudessem aperfeiçoar suas publicações (Rio Grande do Sul. Boletim do CPOE, 1956-1957; 1958). Sobre a Comissão, o Boletim 1958 indicava também que:

No desempenho de suas funções, tem a Comissão procurado não apenas criticar as publicações, atendendo à finalidade legal. Empenha-se, também, vivamente, em contribuir para o saneamento moral das revistas, a fim de que possam circular livremente como meio de recreação sadia. Sendo assim, poderão concorrer para a constante elevação do nível cultural, dentro dos fundamentos filosóficos que norteiam os princípios democráticos da nação brasileira (Rio Grande do Sul. Boletim do CPOE,1958, p 311).

A finalidade legal referida no excerto acima era o atendimento, segundo os pareceristas da Comissão, à Lei Nacional da Imprensa, de 1953 (Brasil. Lei n ${ }^{\circ}$ 2083, de 
12/11/53), e ao Decreto Estadual 5922 (Rio Grande do Sul. Decreto n ${ }^{0}$ 5922, de 14/01/1954). Este último previa, entre outras coisas, que revistas ou publicações deveriam ser enviados a SEC dentro de um prazo de 30 dias após a publicação para avaliação. Se a Comissão designada considerasse que aqueles materiais abordavam de maneira preponderante a violência, os super-homens e as histórias imorais, os mesmos eram taxados em $80 \%$ de imposto sobre as vendas ou consignações (Rio Grande do Sul. Boletim do CPOE, 1958, p. $310)$.

O Boletim do CPOE de 1958 reproduz, na íntegra, a Comunicação que a Comissão apresentou no III Congresso Nacional de Professores Primários. Esse artigo começa com "as palavras de Jesus Cristo, o Mestre dos Mestres" e continua citando o evangelho do apóstolo São Mateus (28:6) ao afirmar que "o que escandalizar a um dêstes pequeninos que crêem em Mim, melhor lhe fôra se lhe pendurasse ao pescoço uma pedra de moinho e o lançassem ao fundo do mar" (Rio Grande do Sul. Boletim do CPOE, 1958, p. 310).

São utilizadas, ainda, as palavras do Papa Leão XII sobre a liberdade de imprensa e as do Cardeal Arcebispo do Rio de Janeiro, D. Jaime Câmara como argumento para o trabalho de classificação da literatura realizado pela Comissão. Um dos argumentos desse trabalho é a necessidade da conjugação de esforços da família, da escola, da Igreja e do Estado na "difusão da boa literatura" com o intuito da "formação de uma moral sadia" entre as "futuras gerações", uma vez que pela literatura seria possível, entre outras coisas, afastar a juventude da corrupção, do vício, da violência, da desordem, do crime (Rio Grande do Sul. Boletim do CPOE, 1958).

Havia, portanto, uma crença incondicional no poder da leitura, tanto para o "bem como para o mal”. Entretanto, nesta mesma comunicação é referido que a Comissão examinava as obras com objetividade e baseada em "opiniões abalizadas emitidas por estudiosos da matéria não só nacionais, como estrangeiras. Inclui-se, aqui, a contribuição valiosa dos estudos e pesquisas realizados pelo Instituto Nacional de Estudos Pedagógicos" (Rio Grande do Sul. Boletim do CPOE, 1958, p. 312).

A Comissão procurou controlar as leituras de crianças, adolescente e jovens gaúchos chamando para si a responsabilidade do saneamento moral da população. As listas com a classificação das revistas em recomendáveis, aceitáveis, aceitáveis com restrições, aceitáveis com restrições à linguagem, aceitáveis a critério dos pais, desaconselháveis, reprováveis e proibidas mediante portaria do juizado de menores eram publicadas no Boletim do CPOE e também enviadas por meio de correspondência a todas as Delegacias de Ensino e prefeituras dos municípios gaúchos. 
Eram utilizados como critérios para a avaliação das obras encaminhadas a SEC e para a elaboração das listas uma classificação legal de acordo com a legislação do período e uma classificação pedagógica amparada pelos "fundamentos da educação" e pelos "princípios morais da família brasileira". A apreciação das revistas considerava ainda os seguintes aspectos: i) o tema; ii) o ambiente; iii) a linguagem; iv) a ilustração; v) a estética da apresentação; vi) a higiene da leitura; e vii) a adequação ao público designado (Rio Grande do Sul. Boletim do CPOE, 1958, p. 307-312).

Apresentamos, a seguir, parte da nominata das publicações analisadas pela Comissão. Pela extensão das listas, foram reproduzidas apenas as revistas recomendadas e as reprovadas, daquelas classificadas em 1957 e publicadas no Boletim do CPOE de 1958.

QUADRO 1. REVISTAS RECOMENDÁVEIS PELA COMISSÃO ESPECIAL DE ESTUDO E CLASSIFICAÇÃO DE PUBLICAÇÕES PERIÓDICAS.

\begin{tabular}{|c|c|c|c|}
\hline TÍTULO & EDITORA & GÊENERO & CATEGORIA \\
\hline A Família Cristã & Edições Paulinas & Miscelânea & Adultos \\
\hline A Ordem & A. A. Lima & Cultura & Idem \\
\hline A Recreativa & Owen Ranieri Mussolin & Enigmista & Idem \\
\hline Ave Maria & P. P. Claret & Religião & Todos \\
\hline Bem-Te-Vi & Fernando Buonaduce & Miscelânea & Infantil \\
\hline Brasil Enigmista & Irineu Villas Boas Esteves & Enigmista & Adultos \\
\hline Cacique & $\begin{array}{l}\text { Secretaria de Educação e } \\
\text { Cultura-R.G. do Sul }\end{array}$ & Miscelânia & Inf. Juvenil \\
\hline Casa e Jardim & Monumento S.A & Decoração & Todos \\
\hline $\begin{array}{l}\text { Ciência em } \\
\text { Quadrinhos }\end{array}$ & Ebal & Ciência & Adulto \\
\hline $\begin{array}{l}\text { Coquetel de Palavras } \\
\text { Cruzadas }\end{array}$ & Tecnoprint Gráfica S.A & Enigmista & Idem \\
\hline $\begin{array}{l}\text { Enciclopédia em } \\
\text { Quadrinhos }\end{array}$ & Rio Gráfica & Cultura & Juvenil \\
\hline Enigmística Moderna & O R Mussolin & Idem & Adultos \\
\hline Era uma vez... & S. Maria & Miscelânia & Infantil \\
\hline
\end{tabular}




\begin{tabular}{|c|c|c|c|}
\hline Espírito Santo & Albano Issler & Religião & Adultos \\
\hline Estudos & A Câmara & Cultura & Idem \\
\hline Estrela do Mar & Pe. Luiz Rem & Religião & Juvenil \\
\hline Flores do Carmelo & Padres Carmelitas & Idem & Adultos \\
\hline Lady & Monumento S A & Miscelânia & Feminina \\
\hline La Família & Libros y Revistas SA & Modas & Idem \\
\hline Leitores e Livros & Liga Universitária Católica & Cultura & Adultos \\
\hline Mundo Agrícola & Mundo Agrícola & Técnica & Agricultores \\
\hline Nosso Amiguinho & M. Malty & Miscelânia & Inf. Juvenil \\
\hline O Apóstolo do S.S & P.P.Sacramentinos & Religião & Adultos \\
\hline O Crisol & Homero Mazarem Brum & Miscelânia & Inf. Juvenil \\
\hline O Éco & P. Inácio Valle S. J. & Religião & Juvenil \\
\hline Palavras Cruzadas & Tecnoprint Gráfica S.A & Enigmista & Adultos \\
\hline Palavrinhas Cruzadas & Idem & Idem & Inf. Juvenil \\
\hline Parque de Diversões & Idem & Idem & Juvenil \\
\hline Pinguinho & O Malho & Miscelânia & Infantil \\
\hline Revista da Asa & R. Poyares & Cultura & Adultos \\
\hline $\begin{array}{l}\text { Revista de } \\
\text { Automóveis }\end{array}$ & Murillo Reis & Técnica & Idem \\
\hline Revista do Ensino & $\begin{array}{l}\text { Secretaria de Educação e } \\
\text { Cultura-R. G. do Sul }\end{array}$ & Educação & Professores \\
\hline Série Sagrada & Ebal & Religião & Todos \\
\hline Sesinho & SESI & Miscelânia & Inf. Juvenil \\
\hline Tiquinho & O Malho & Idem & Infantil \\
\hline Grandes Figuras & Ebal & Cultura & Todos \\
\hline
\end{tabular}

Fonte: Rio Grande do Sul. Boletim do CPOE, 1958, p. 313.

O quadro 1 apresenta as trinta e seis revistas consideradas como recomendáveis pela Comissão. Foi possível constatar que entre essas o gênero literário variava entre nove classificações (27,77\% miscelânia; 19,44\% religião; 19,44\% cultura; 16,66\% enigmista; $5,55 \%$ técnica; $2.77 \%$ ciência; $2,77 \%$ decoração; $2,77 \%$ educação; e $2,77 \%$ modas); e as 
categorias entre oito $(41,66 \%$ adultos; $13,88 \%$ infanto-juvenil; $11,11 \%$ infantil; $11,11 \%$ juvenil; $11,11 \%$ todos; $5.55 \%$ feminina; $2.77 \%$ agricultores; e $2.77 \%$ professores). Entre as editoras vinte e oito obtiveram a aprovação de publicações, dentre as quais somente a "Ebal", a "Monumento S.A", a "O.R. Mussolin", a "Secretaria de Educação e Cultura do R. G. do Sul" e a "Tecnoprint Gráfica S.A" possuíam mais de uma revista aprovada.

QUADRO 2: REVISTAS REPROVÁVEIS PELA COMISSÃO ESPECIAL DE ESTUDO E CLASSIFICAÇÃO DE PUBLICAÇÕES PERIÓDICAS.

\begin{tabular}{|c|c|c|c|}
\hline TITULO & EDITORA & GENNERO & CATEGORIA \\
\hline Amor em Revista & Jornal das Moças & Miscelânea & Juvenil \\
\hline Artelândia & Brasilidade & - & Adultos \\
\hline Bem-me-quer & Orbis & Romance & Juvenil \\
\hline Biriba & Rio Gráfica & Aventuras & Idem \\
\hline Brasilidade & Brasilidade & - & Adultos \\
\hline Capitão Fantasma & Tecnoprint Gráfica & Aventuras & Idem \\
\hline Casos de Amor & Orbis & Romance & Idem \\
\hline Contos de Terror & La Selva & Terror & Adultos \\
\hline Correio Sentimental & Brasilidade & Romance & Idem \\
\hline Dick Tracy & Rio Gráfica & Aventuras & Juvenil \\
\hline Detetive & O Cruzeiro & Policial & Adultos \\
\hline Gato Preto & Seleções em Quadrinhos & Terror & Idem \\
\hline Guerra ao Crime & Tecnoprint Gráfica & Policial & Idem \\
\hline $\begin{array}{l}\text { Manon } \quad \text { (Grandes } \\
\text { Amores) }\end{array}$ & Abreu & Idem & Idem \\
\hline Medo & - & Terror & Idem \\
\hline Modelos & - & Fotografias & Idem \\
\hline Mundo das Sombras & Seleções em Quadrinhos & Terror & Idem \\
\hline Namorada & Tecnoprint Gráfica & Romance & Juvenil \\
\hline Noites de Terror & Seleções em Quadrinhos & Terror & Adultos \\
\hline Policia & R. Unidas & Policial & Idem \\
\hline Revista Policial & L. Piranema & Policial & Idem \\
\hline Rumba & Giorgette & Romance & Juvenil \\
\hline
\end{tabular}




\begin{tabular}{|l|l|l|l|}
\hline Sobrenatural & - & Idem & Idem \\
\hline Scotland Yard & Rio Gráfica & Aventuras & Idem \\
\hline Terror Negro & La Selva & Terror & Adultos \\
\hline Vida e Beleza & - & Nudismo & Idem \\
\hline Xuxa & Vecchi & Aventuras & Juvenil \\
\hline
\end{tabular}

Fonte: Rio Grande do Sul. Boletim do CPOE, 1958, p. 317-318.

No que diz respeito ao quadro 2, que apresenta as vinte e sete revistas reprovadas pela Comissão, foram identificadas oito variantes no gênero literário (22.22\% romance; $22.22 \%$ terror; $18.51 \%$ aventuras; $18.51 \%$ policial; $3.70 \%$ fotografias; $3.70 \%$ miscelânea; $3.70 \%$ nudismo; e $7.40 \%$ não catalogados) e apenas duas categorias (66.66\% adultos; e $33.33 \%$ juvenil). O número de editoras que sofreram com a reprovação de suas publicações totaliza quatorze, sendo que entre essas as de maior representatividade foram a "Brasilidade", a "Rio Gráfica", a "Seleções em Quadrinhos" e a "Tecnoprint Gráfica", cada uma com a reprovação de três revistas.

A partir dos dados expostos nos quadros 1 e 2 podemos constatar que nas revistas recomendadas predominam os gêneros literários miscelânia, religião e cultura e as categorias adultos, infanto-juvenil, infantil e juvenil. Por outro lado, nas revistas reprováveis sobressaíam os gêneros romance, terror e aventura e apenas as categorias adultos e juvenil. Em relação as editoras observamos a atuação de trinta e oito órgãos que submeteram para a avaliação da Comissão sessenta e três revistas.

\section{A Revista do Ensino e sua atuação no "saneamento" da literatura infanto-juvenil}

A Revista do Ensino foi um periódico pedagógico gaúcho que teve várias fases. A primeira delas entre os anos de 1939 a 1942, foi publicada sob o patrocínio da Secretaria de Educação e Saúde Pública. Após nove anos de interrupção, em 1951, a Revista voltou a circular como iniciativa de um grupo de professoras primárias. E, em 1956, passou a ser a publicação oficial sob a supervisão do CPOE. Na década de 70, a Revista passou novamente por uma série de dificuldades e de forma bastante irregular foi publicada até os anos 90 (BASTOS, 2005).

Nos interessa, neste trabalho, a segunda fase da revista, ou seja, a dos anos 50, porque coincide com o período do trabalho do CPOE, em geral, e da Comissão Especial de Estudo e 
Classificação de Publicações Periódicas, em especial. Nesse momento, o periódico procurava se constituir como "um instrumento técnico-pedagógico de atualização permanente do magistério, elevando nível quantitativo dos profissionais da educação, através da divulgação de experiências pedagógicas, da realidade da educação e do ensino” (BASTOS, 2005, p. 339).

A Revista do Ensino publicava comunicados do CPOE, orientações sobre os programas de ensino, reportagens sobre experiências pedagógicas, entrevistas com educadores considerados relevantes, notícias de eventos, sugestões de exercícios, letras de músicas, poemas, entre outros. Textos que abrangiam a temática da literatura infanto-juvenil eram correntes, consistindo em um total de trinta e dois textos durante a década de 1950. Cabe destacar que para a construção do quadro 3, apresentado abaixo, todos os exemplares da Revista do Ensino da década de 1950 foram lidos e fichados.

QUADRO 3. ARTIGOS PUBLICADOS NA REVISTA DO ENSINO SOBRE A TEMÁTICA DE LITERATURA INFANTO-JUVENIL.

\begin{tabular}{|c|c|c|c|}
\hline AUTORES & TÍTULO & $P A ́ G$. & $E D I C ̧ \tilde{A} O$ \\
\hline- & Livros. & 69 & Ano I, n. 1, 1951. \\
\hline $\begin{array}{l}\text { Hélia de Carvalho } \\
\text { Armando. }\end{array}$ & $\begin{array}{l}\text { Considerações sobre a Literatura } \\
\text { Infantil }\end{array}$ & $65-66$ & Ano I, n. 2, 1951. \\
\hline Edith Bueno Romero & Literatura infantil: Comentando. & 51 & Ano I, n. 5, 1952. \\
\hline $\begin{array}{l}\text { Elida de Freitas e } \\
\text { Castro Duck }\end{array}$ & Biblioteca Escolar Infantil. & 44 & Ano I, n. 6, 1952. \\
\hline- & Literatura infantil. & 12 & $\begin{array}{l}\text { Ano III, n. 20, } \\
1954 .\end{array}$ \\
\hline Malba Tahan & $\begin{array}{l}\text { Curso de Aperfeiçoamento. } \\
\text { Programa de Literatura Infantil. }\end{array}$ & $54-56$ & $\begin{array}{l}\text { Ano IV, n. } 25, \\
1954 .\end{array}$ \\
\hline $\begin{array}{l}\text { Elida de Freitas e } \\
\text { Castro Duck }\end{array}$ & $\begin{array}{l}\text { Biblioteca Escolar Infantil. Frases } \\
\text { Sugestivas. }\end{array}$ & $12-13$ & $\begin{array}{l}\text { Ano IV, n. 26, } \\
\text { 1954. }\end{array}$ \\
\hline $\begin{array}{l}\text { Elida de Freitas e } \\
\text { Castro Duck }\end{array}$ & $\begin{array}{l}\text { Biblioteca Escolar Infantil. Uma } \\
\text { Biblioteca em Ação. }\end{array}$ & $21-22$ & $\begin{array}{l}\text { Ano IV, n. 27, } \\
1954 .\end{array}$ \\
\hline $\begin{array}{l}\text { Elida de Freitas e } \\
\text { Castro Duck }\end{array}$ & $\begin{array}{l}\text { Biblioteca Escolar Infantil. } \\
\text { Campanha da Boa Revista. }\end{array}$ & $21-23$ & $\begin{array}{l}\text { Ano IV, n. 28, } \\
1955 .\end{array}$ \\
\hline Elida $\quad$ de $\quad$ Freitas $\mathrm{e}$ & Biblioteca & $19-20$ & Ano IV, n. 29, \\
\hline
\end{tabular}




\begin{tabular}{|c|c|c|c|}
\hline Castro Duck & Campanha da Boa Revista. & & 1955. \\
\hline $\begin{array}{l}\text { Elida de Freitas e } \\
\text { Castro Duck }\end{array}$ & $\begin{array}{l}\text { Biblioteca Escolar Infantil. } \\
\text { Campanha da Boa Revista. }\end{array}$ & $23-24$ & $\begin{array}{l}\text { Ano IV, n. } 30 \text {, } \\
1955 .\end{array}$ \\
\hline $\begin{array}{l}\text { Elida de Freitas e } \\
\text { Castro Duck }\end{array}$ & $\begin{array}{l}\text { Biblioteca Escolar Infantil. A } \\
\text { criança e o livro. }\end{array}$ & 12 & $\begin{array}{l}\text { Ano IV, n. 31, } \\
1955 .\end{array}$ \\
\hline Lenyra C. Fraccaroli & $\begin{array}{l}\text { Literatura Infantil: da Bibliografia } \\
\text { da Literatura Infantil em língua } \\
\text { portuguesa. }\end{array}$ & 72 & $\begin{array}{l}\text { Ano IV, n. 32, } \\
1955 .\end{array}$ \\
\hline Antonietta Barone & $\begin{array}{l}\text { Biblioteca Escolar. Literatura } \\
\text { Infantil. }\end{array}$ & $42-43$ & $\begin{array}{l}\text { Ano V, n. 38, } \\
1956 .\end{array}$ \\
\hline - & $\begin{array}{l}\text { Orientação Bibliográfica. Livros } \\
\text { Infantis. }\end{array}$ & 67 & $\begin{array}{l}\text { Ano V, n. 39, } \\
1956 .\end{array}$ \\
\hline- & $\begin{array}{l}\text { Bibliografias. Orientação: livros } \\
\text { para o mestres, didáticos e } \\
\text { infantis. }\end{array}$ & 72 & $\begin{array}{l}\text { Ano VI, n. 40, } \\
1956 .\end{array}$ \\
\hline $\begin{array}{l}\text { Edissa Zulmires de } \\
\text { Campos }\end{array}$ & $\begin{array}{l}\text { Literatura infantil. Precisamos de } \\
\text { melhores revistas para as crianças. }\end{array}$ & $48-57$ & $\begin{array}{l}\text { Ano VI, n. 41, } \\
1956 .\end{array}$ \\
\hline - & Bibliografias. Literatura Infantil. & 20 & $\begin{array}{l}\text { Ano VI, n. 43, } \\
1957 .\end{array}$ \\
\hline Lucia Minssen & $\begin{array}{l}\text { Literatura infantil. Aprendendo a } \\
\text { selecionar. }\end{array}$ & 11 & $\begin{array}{l}\text { Ano VI, n. 46, } \\
1957 .\end{array}$ \\
\hline- & $\begin{array}{l}\text { Processos auxiliares de ensino. A } \\
\text { narrativa de histórias e o gosto } \\
\text { pelo boa leitura. }\end{array}$ & $9-10$ & $\begin{array}{l}\text { Ano VII, n. 54, } \\
1958 .\end{array}$ \\
\hline Generice A. Vieira & Comentário Bibliográfico. & $60-61$ & $\begin{array}{l}\text { Ano VIII, n. 55, } \\
1958 .\end{array}$ \\
\hline Generice A. Vieira & Comentário Bibliográfico. & $60-61$ & $\begin{array}{l}\text { Ano VIII, n. 57, } \\
1958 .\end{array}$ \\
\hline- & $\begin{array}{l}\text { Informações Bibliográficas. } \\
\text { Bibliografia Infantil. }\end{array}$ & 61 & $\begin{array}{l}\text { Ano VIII, n. 57, } \\
1958 .\end{array}$ \\
\hline Generice A. Vieira & Comentário Bibliográfico. & $61-62$ & $\begin{array}{l}\text { Ano VIII, n. 58, } \\
1958 .\end{array}$ \\
\hline- & Bibliografias. & 61 & Ano VIII, n. 58, \\
\hline
\end{tabular}




\begin{tabular}{|l|l|l|l|}
\hline $\begin{array}{l}\text { Yonne Ribeiro Moraes } \\
\text { e Ilka Guittes Neves }\end{array}$ & $\begin{array}{l}\text { Normas para julgamento de } \\
\text { publicações periódicas. }\end{array}$ & 38 & $\begin{array}{l}\text { Ano VIII, n. 59, } \\
1959 .\end{array}$ \\
\hline Generice A. Vieira & Comentário Bibliográfico. & 45 & $\begin{array}{l}\text { Ano VIII, n. 59, } \\
1959 .\end{array}$ \\
\hline Generice A. Vieira & Comentário Bibliográfico. & $60-61$ & $\begin{array}{l}\text { Ano VIII, n. 60, } \\
1959 .\end{array}$ \\
\hline Generice A. Vieira & Comentário Bibliográfico. & $46-47$ & $\begin{array}{l}\text { Ano VIII, n. 61, } \\
1959 .\end{array}$ \\
\hline Generice A. Vieira & $\begin{array}{l}\text { Agora os debates sobre Literatura } \\
\text { começam na Escola Primária. }\end{array}$ & $12-14$ & $\begin{array}{l}\text { Ano VIII, n. 62, } \\
1959 .\end{array}$ \\
\hline Generice A. Vieira & Comentário Bibliográfico. & 60 & $\begin{array}{l}\text { Ano VIII, n. 62, } \\
1959 .\end{array}$ \\
\hline Generice A. Vieira & Bibliografia Comentada & 60 & $\begin{array}{l}\text { Ano IX, n. 65, } \\
1959 .\end{array}$ \\
\hline
\end{tabular}

Fonte: Revista do Ensino (década de 1950). Elaborado pelas autoras.

No artigo denominado Precisamos de melhores revistas para as crianças, de Edissa Zulmires de Campos, professora de Metodologia do Ensino Primário do Instituto Feminino de Educação Padre Anchieta em São Paulo era ressaltado a necessidade do "policiamento e proibição da venda das publicações condenadas" e da "melhoria das revistas consideradas aceitáveis" (Revista do Ensino, ano 6, n. 41, 1956, p. 50). Abaixo a reprodução da classificação de algumas revistas infanto-juvenis:
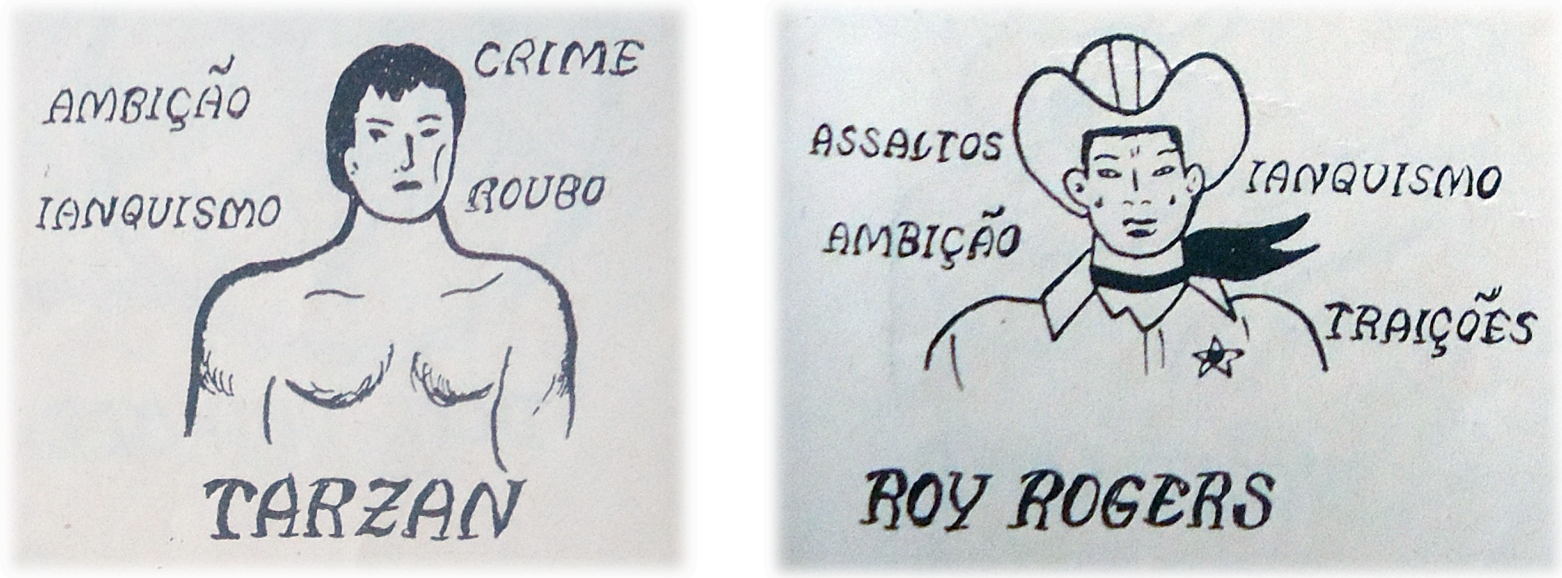
Fonte: Revista do Ensino, ano 6, n. 41, 1956, p. 51.

As revistas infanto-juvenis Aí Mocinho, Biriba, Capitão Marvel, Cavaleiro Negro, Dom Quixote, Durango Kid, Fantasma, Gibi, Gilda, Globo Juvenil, Grande Hotel, Guri, Rocki Lane, Rosalinda, Super-Homem, Terror Negro e Zorro foram classificadas como perniciosas por não atenderem os aspectos educativos e artísticos entendidos como desejados e por conterem elementos relacionados a crimes, roubos, assaltos, raptos, falsificações, assassinatos, espionagens e ianquismos (Revista do Ensino, ano 6, n. 41, 1956, p. 50).

Um outro texto denominando Aprendendo a Selecionar, de Lucia Minssen, Diretora da Biblioteca Pública Infantil de Porto Alegre, publicado na Revista do Ensino, a autora salientava que "sérias medidas devem ser tomadas imediatamente. Livros devem estar à disposição das crianças, mas livros bons, que atendam os objetivos de formação visados pela educação", e questionava ainda a compra desses materiais de maneira aleatória ou por critérios relacionados ao "preço camarada" (Revista do Ensino, ano 6, n. 46, 1957, p. 11).

A Comissão Especial de Estudo e Classificação de Publicações Periódicas também utilizou a Revista do Ensino para apresentar os aspectos considerados prejudiciais na literatura infanto-juvenil, tais como a "supervalorização da força física", o "desrespeito ou desacato à autoridade constituída", o "desquite tratado humoristicamente ou representado como desejável", o "desrespeito a vida familiar e a autoridade dos pais", as "cenas de horror", as "figuras femininas com exagero dos atributos físicos ou semivestidas", a "falta de nitidez e adequação ao texto", os "estrangeirismos desnecessários" e a "divulgação de costumes estranhos à formação do povo brasileiro" (Revista do Ensino, ano 8, n. 59, 1959, p. 38).

Sob o designação de Comentários Bibliográficos ou Informações Bibliográficas a Revista do Ensino publicava listas de livros recomendados seguidas de comentários. Por exemplo, em agosto de 1959, a revista publicou uma lista de dez títulos. Desses, oito são da Condessa de Ségur, um de Viriato Correia e outro de Vicente Guimarães. Os títulos são os seguintes: "Cazuza”, "Marisa”, “A Filha da Mireninha”, “As Meninas Exemplares”, "A Casa do Anjo da Guarda", "Que Amor de Criança", "Os Dois Patetas", “As Férias", "A Irmã do Simplicio", "Braz e a Primeira Comunhão" (Revista do Ensino, ano 8, n. 62, 1959, p. 60).

Todos os títulos eram seguidos de comentários que abrangiam a autoria, a editora, o aspecto material, o gênero, o valor educativo, a linguagem, a série, as observações e o conteúdo, conforme pode ser percebido pelo o extrato a seguir: 
Autora: Condessa de Ségur

Editora: Editora do Brasil

Aspecto material: Bom

Gênero: Literário (realista)

Valor educativo: Construtivo

Linguagem: Correta

Série: escolar

Observação: Toda menina deveria ler este livro. Os personagens pensam, sentem e agem de uma forma muito delicada e correta.

Conteúdo: Ocorrências diárias da vida de uma pequena família mãe e duas filhas pequenas (Revista do Ensino, ano 8, n. 62, p. 60).

A recomendação dos livros da Condessa de Ségur é frequente nas listas do CPOE e da Revista do Ensino, assim, cabe desenvolver algumas considerações sobre a autora e suas obras. Condessa de Ségur chamava-se Sofia Fedorovna Rostopchina, nascida em 1799, em São Petersburgo, na Rússia e falecida em Paris, em 1874. Em razão de perseguições políticas, sua família abandonou a Rússia em 1817 e exilou-se em Paris, local onde viveu até a sua morte aos 75 anos. Em 1819 Sofia casou-se com o Conde Eugène de Ségur, daí seu título, com quem teve 8 filhos. Teria começado a escrever aos 50 anos para as netas que vivam em Londres. Ao tratar da obra da Condessa de Ségur, Magalhães e Alçada (1990) salientam que:

(...) a escritora esquece-se de si própria e escreve não só para educar mas, sobretudo, para distrair as crianças. As suas narrativas são sempre ligeiras. Mesmo quando trata assuntos sérios o peso da alegria é maior que o da tristeza (...). A Condessa de Ségur fala do mundo que conhece. A maior parte das suas personagens vive em palácios, tem criados e carruagens, passa o Verão no campo e o Inverno em Paris. Entre a aristocracia, entre aqueles que os servem há problemas diversos de saúde, de falta de carinho, de solidão e morte. Mas ao sofrimento a escritora contrapõe constantemente cenas cómicas, alegres e dá às suas histórias um desfecho que deixa o público dormir descansado (MAGALHÃES e ALÇADA, 1990, p. 5-6).

O livro "As Meninas Exemplares" narra as aventuras da rebelde Sofia, uma menina órfã que após a morte de seu pai ficou morando com sua atroz madrasta, a senhora de Fichini. Sua vida muda quando a madrasta necessita viajar e a deixa sob os cuidados da 'adorável' vizinha, a senhora Fleurville. A nova casa já abrigava duas crianças, Camila e Madalena, e Sofia inspirada pela acolhida calorosa e pelo bom exemplo dado pelas outras meninas transforma seu comportamento, passando agir de maneira educada e gentil.

A constância no número de indicações da obra da Condessa de Ségur, que possui personagens que inspiram uma postura dócil, compreensiva e obediente, exemplifica o perfil da atuação da Revista do Ensino. Esse periódico tencionava colaborar com o aumento da 
circulação de livros e revistas entre as crianças e os adolescentes. No entanto, os livros e as revistas deveriam ser identificados com a 'boa' leitura e recomendados pelos órgãos competentes.

\section{Considerações Finais}

Uma conjuntura de apreensão no que concerne ao provável alcance e influência da imprensa voltada para o público infanto-juvenil afligiu, durante a década de 1950, órgãos educacionais de destacada atuação no Rio Grande do Sul. O CPOE instituiu a Comissão Especial de Estudo e Classificação de Publicações Periódicas e a Revista do Ensino a seção de Comentários Bibliográficos ou Informações Bibliográficas. Em ambos os casos havia uma tentativa de estabelecer um 'saneamento' das publicações.

As ações da Comissão Especial de Estudo e Classificação de Publicações Periódicas e da Revista do Ensino foram conduzidas a partir de um amparo legal e inspiradas em um discurso que evocava como palavras-chave a Escola, a Família, a Igreja e o Estado. Uma postura de vigilância foi instituída em relação aos livros e as revistas que poderiam influenciar a 'formação moral' das crianças e dos jovens. Esses órgãos fiscalizadores classificavam os materiais, apontavam falhas, sugeriam modificações e taxavam aqueles que fossem considerados impróprios.

No desenvolvimento do trabalho observamos algumas estratégias de difusão daquilo que era considerado adequado pela Comissão e pela Revista do Ensino como, por exemplo, a divulgação de nominatas recomendando ou reprovando impressos. No rol de materiais para leitura 'salutares' estavam presentes os gêneros miscelânea e cultura, as publicações da própria SEC, como a "Cacique", as revistas de vinculação religiosa explícita, como "A Família Cristã", "A Ordem", "Ave-Maria" e "Espírito Santo" e autores como a Condessa de Ségur.

No que diz respeito às publicações não recomendadas percebemos uma campanha contra os impressos que contivessem elementos que inspirassem o desrespeito à autoridade $\mathrm{e}$ a vida familiar, aludissem a cenas de horror e violência e que divulgassem os estrangeirismos. Em um contexto histórico nacionalista as avaliações consideravam as revistas em quadrinhos, como "Tarzan" e "Capitão Marvel”, prejudiciais por conterem costumes avaliados como diferentes 'do povo brasileiro'. Entretanto, se leitores e leitoras pautaram suas leituras pelas 
classificações do CPOE e da Revista do Ensino já é uma outra história... Talvez, e infelizmente, irrecuperável!

\section{Referências}

BASTOS, M. H. C. A Revista do Ensino do Rio Grande do Sul (1939-1942): o novo e o nacional em revista. Pelotas: Seiva Publicações, 2005.

BRASIL. Lei $n^{\circ}$ 2083. Regula a Liberdade de Imprensa. 12 de nov. 1953. Disponível em: $<$ http://www2.camara.gov.br/legin/fed/lei/1950-1959/lei-2083-12-novembro-1953-366187publicacaooriginal-1-pl.html>. Acesso em: 20 de out. 2012.

MAGALHÃES, A. M. E ALÇADA, I. (1990). Literatura infantil: espelho da alma, espelho do mundo. Revista ICALP. On-line, v. 20-21, p. 1-13, outubro de 1990. Disponível em: $<\mathrm{http}: / / \mathrm{cvc}$.instituto-camoes.pt/bdc/revistas/revistaicalp/litinfantil.pdf $>$. Acesso em: 20 de out. 2012.

PERES, E. Aprendendo formas de pensar, se sentir e de agir: discursos pedagógicos e práticas escolares na escola pública. Tese (Doutorado em Educação), Universidade Federal de Minas Gerais, Belo Horizonte, 2000.

QUADROS, C. Reforma, ciência e profissionalização da educação: o Centro de Pesquisas e Orientação Educacionais do Rio Grande do Sul. Tese (Doutorado em Educação), Universidade Federal do Rio Grande do Sul, Porto Alegre, 2006.

QUADROS, C. e STEPHANOU, M. Reforma educacional e produção de modos de ser e pensar: A experiência do Rio Grande do Sul nos anos 30 a 50 do século 20. Revista Lusófona de Educação. Lisboa, n. 18, p. 97-110, 2011. Disponível em: $<$ http://redalyc.uaemex.mx/redalyc/pdf/349/34922201007.pdf>. Acesso em: 20 de out. 2012.

REVISTA DO ENSINO. Exemplares de 1951-1960. Acervo do Grupo de Pesquisa HISALES da Faculdade de Educação da Universidade Federal de Pelotas.

RIO GRANDE DO SUL. Decreto $n^{\circ}$ 578. 22 de jul. 1942. Acervo da Biblioteca da Assembleia do Estado do Rio Grande do Sul.

RIO GRANDE DO SUL. Decreto $n^{\circ}$ 794. 17 de jun. 1943. Acervo da Biblioteca da Assembleia do Estado do Rio Grande do Sul.

RIO GRANDE DO SUL. Decreto $n^{o} 5922.14$ de janeiro de 1954. Acervo da Biblioteca da Assembleia do Estado do Rio Grande do Sul.

RIO GRANDE DO SUL. Secretaria de Educação e da Cultura do Rio Grande do Sul. Boletim do CPOE 1947. 1947. Acervo do Grupo de Pesquisa HISALES/FaE/UFPEL.

RIO GRANDE DO SUL. Secretaria de Educação e da Cultura do Rio Grande do Sul. Boletim do CPOE 1952-1953. 1953. Acervo do Grupo de Pesquisa HISALES/FaE/UFPEL.

RIO GRANDE DO SUL. Secretaria de Educação e da Cultura do Rio Grande do Sul. Boletim do CPOE 1956-1957. 1957. Acervo do Grupo de Pesquisa HISALES/FaE/UFPEL.

RIO GRANDE DO SUL. Secretaria de Educação e da Cultura do Rio Grande do Sul. Boletim do CPOE 1958. 1958. Acervo do Grupo de Pesquisa HISALES/FaE/UFPEL. 
RIO GRANDE DO SUL. Secretaria de Educação e da Cultura do Rio Grande do Sul. Boletim do CPOE 1959. 1959. HISALES/FaE/UFPEL.

VENTORINI, E. Regulação da leitura e da literatura infanto-juvenil, no Rio Grande do Sul, na década de 1950: interdição, triagem e intervenção das autoridades. Dissertação (Mestrado em Educação), Universidade Federal do Rio Grande do Sul, Porto Alegre, 2009.

VENTORINI, E. Juventude, leituras infames e educação. In: BARROSO, V. L. et al. Ensino de História: desafios contemporâneos. Porto Alegre: ANPUH-RS, 2010. p. 87-100.

ARTIGO ENVIADO EM: 06/01/2015

ACEITO PARA PUBLICAÇÃO EM: 12/02/2015 